\title{
EVALUASI KESESUAIAN LAHAN PERTANIAN PADA AREAL PENGGUNAAN LAIN UNTUK TANAMAN KOPI ARABIKA(Coffea arabica L.) DI KECAMATAN SALAK KABUPATEN PAK-PAK BHARAT
}

\author{
Budi Hartono ${ }^{1}$, Abdul Rauf' ${ }^{1}$, Deni Elfiati ${ }^{2}$, Fitra Syawal Harahap ${ }^{3}$ dan Simon \\ Haholongan Sidabuke ${ }^{4}$ \\ ${ }^{1}$ Program Pasca Sarjana Agroteknologi Fakultas Pertanian Universitas Sumatera Utara 20222 \\ ${ }^{2}$ Fakultas Kehutanan Universitas Sumatera Utara 20222 \\ ${ }^{3}$ Program Studi Budidaya Perkebunan Universitas Tjut Nyak Dhien Medan 20123 \\ ${ }^{4}$ Program Studi Manajemen Kehutanan Fakultas Pertanian Universitas Simalungun 21142 \\ Email: fitrasyawalharahap@gmail.com, hartonobudi901@.gmail.com
}

\begin{abstract}
Based on the Decree of the Minister of Forestry Number. 44 of 2005 on Appointment of Forest Areas in North Sumatra Province. The total area of forest in Pakpak Bharat Regency based on the decree is 120,711 ha $(88.60 \%$ of the total of Pakpak Bharat Regency), with details 1) Natural Forest Reserve 4.36\%, 2) Limited Production Forest 41.95\%, 3) Protection Forest 34.61\%, 4) Forest Production 7.68\%. Subsequently, the Decree was revised with Decree No. Menhut. 579 / Menhut-II / 2014 in accordance with the proposed revision of forest area by Pakpak Bharat government. With the decree, the forest area released into Other Use Areas (APL) is only a small portion of the proposed area so that APL Land Use (Area of Other Use) in Salak Sub-district needs to be supported with information on land suitability of course very potential land to be utilized in activities cultivation of agriculture, with the hope that productivity can improve the welfare of local people who mostly work as farmers. The objectives of this study were to evaluate the characteristics of the APL land suitability level, to analyze improvement efforts to increase productivity, and to map actual land suitability and potential land suitability for coffee crops on APL land in Salak Subdistrict. The research method used survey method. Unit unit of land based on land map, slope slope map, altitude map, land cover map, and consists of 8 land units and 18 sampling points. Research data were analyzed using matching method. Research results Limiting factors and improvement efforts of plant commodities Coffee Plant (Coffea arabica L.) Rooting factor factor (rc) and nutrient retention (nr). Improvement efforts that can be done is making drainage and calcification $\mathrm{CaCo} 3$
\end{abstract}

Key words : Land suitability, Coffee, District Salak

(C) 2018 Budi Hartono, Abdul Rauf, Deni Elfiati, Fitra Syawal Harahap, Simon Haholongan Sidabuke

\section{PENDAHULUAN}

Kecamatan Salak memiliki luas lahan Areal Penggunaan Lain (APL) seluas 3.607,20 ha atau $13,67 \%$ dari $25.640,99$ ha total luas APL keseluruhan di Kabupaten Pakpak Bharat (Pemkab Pakpak Bharat, 2014). Dengan luas lahan APL yang cukup luas di kecamatan tersebut tentunya sangat besar potensi lahan untuk dimanfaatkan dalam kegiatan budidaya pertanian, dengan harapan produktivitas tersebut dapat meningkatkan kesejahteraan masyarakat setempat yang sebagian besar berprofesi sebagai petani. Surat Keputusan Menteri Kehutanan Nomor. 44 Tahun 2005 tentang Penunjukan Kawasan Hutan di Provinsi Sumatera Utara. Luas kawasan hutan di Kabupaten Pakpak Bharat berdasarkan SK tersebut adalah 120.711 ha $(88.60 \%$ dari luas Kabupaten Pakpak Bharat), dengan rincian 1) Hutan Suaka Alam 4.36 \%, 2) Hutan Produksi Terbatas $41.95 \%$, 3) Hutan Lindung 34.61\%, 4) Hutan Produksi 7.68\%. Selanjutnya, SK 
tersebut direvisi dengan SK Menhut No. 579/Menhut-II/2014 sesuai dengan permohonan usulan revisi kawasan hutan oleh pemerintah Kabupaten Pakpak Bharat. Dengan SK tersebut, kawasan hutan yang dilepas menjadi Areal Penggunaan Lain (APL) hanya sebagian kecil dari areal yang diusulkan.

Manfaat evaluai lahan bagi lingkungan adalah mencegah terjadinya degradasi lahan. Sedangkan manfaat evaluasi lahan bagi petani adalah meningkatkan efisiensi pengelolaan lahan dan mengoptimalkan produktivitas tanaman. Dan bagi pemerintah, evaluasi lahan bermanfaat sebagai dasar untuk pengembangan sektor pertanian, terutama untuk pemanfaatan kawasan Areal Penggunaan Lain (APL).

Pembukaan areal baru perlu diteliti sumberdaya lahannya guna menentukan kesesuaian lahan untuk penggunaan tertentu, agar lahan tersebut dapat produktif secara berkelanjutan (Dent, 1978 dalam Djomantara dan Rachmawati, 2000). Pemilihan lahan yang sesuai membutuhkan metode dan cara evaluasi kesesuaian lahan yang lebih aktual dan lebih dapat diandalkan, sebagai pedoman dalam upaya pengelolaan lahan untuk dapat mencapai produktifitas normal (Hutapea 1991). Pengelolaan kebun kopi di Provinsi Sumatera Utara sejauh ini masih dilakukan oleh masyarakat melalui pola tradisional dan umumnya dilakukan dengan cara intensif yaitu melalui pembukaan lahan berhutan dan penggunaan sarana produksi kimia dalam pemeliharaan serta perawatannya. Kondisi ini memberikan tanggapan balik yang tidak menguntungkan untuk produktifitas kopi dan keberlanjutan perdagangannya dimasa sekarang dan yang akan datang (Arief et. al, 2011).

Umumnya permasalahan petani kopi di Indonesia adalah mengusahakan tanaman kopi robusta dan kopi arabika secara bersamaan. Tanaman kopi robusta $40 \%$ mendominasi lahan-lahan yang cocok ditanami kopi arabika. Kopi robusta sudah lebih tua, dan perolehan hargannya lebih rendah dibandingkan kopi arabika yang nilai jualnya lebih tingi (Rubiyo et. al., 2003). Di Kabupaten Dairi, Daerah-daerah yang menjadi penghasil kopi arabika antara lain; Sumatera Utara, Aceh, Jawa Timur, Bali, Nusa Tenggara Timur dan lain sebagainya. Indonesia menjadi produsen ke-empat terbesar di dunia untuk penghasil kopi saat ini

Lahan-lahan yang sebelumnya ditanami dengan kopi robusta kini dialihkan untuk tanaman kopi arabika karena harga kopi arabika yang lebih tinggi dibandingkan dengan kopi robusta.Secara geografis, kabupaten Pakpak Bharat terletak diantara koordinat 02¹5'49” - 02०47'08” LU dan 98 4'12” 98 28'01" BT. Kabupaten Pakpak Bharat umumnya berada pada ketinggian rata-rata antara 250-1.400 meter di atas permukaan laut, memiliki keadaan lereng yang bervariasi yaitu mulai dari datar, berombak, bergelombang, curam hingga terjal. Suhu udara berkisar antara $18^{0}$ sampai $28^{\circ} \mathrm{C}$ dengan curah hujan sekitar $3161 \mathrm{~mm} /$ tahun.

Menurut Mukhlis (2007) banyaknya unsur hara atau kapur yang harus diberikan ke sistem tanah tanaman dapat ditentukan secara tepat dengan mengetahui tingkat kesuburan suatu tanah, yang dapat dilakukan dengan cara evaluasi tanah.Untuk mengukur tingkat kesesuaian lahan untuk tanaman kopi dilakukan dengan cara membandingkan karakteristik lahan yang ada di lapangan, dengan tataran idealnya yaitu (S1) sesuai, (S2) agak sesuai dan (S3) tidak sesuai (Hermon dan Khairani, 2009).

Evaluasi sumberdaya lahan merupakan salah satu elemen penting dalam perencanaan atas keputusan suatu wilayah yang akan diperuntukkan untuk apa (Karim, 2007). Berdasarkan hal itu maka perlu dilakukan evaluasi status hara yang ada di kebun Inti Kopi tersebut, sehingga akan dapat diketahui tentang gambaran keadaan hara di dalam tanah yang nantinya dapat digunakan untuk menentukan tindakan pengelolan yang harus dilakukan agar tanaman kopi tumbuh dengan baik dan dapat menghasilkan produksi secara optimum. Tujuan penelitian ini Untuk mengevaluasi karakteristik tingkat kesesuaian lahan aktual dan kesesuaian lahan potensial di Kecamatan Salak sehingga diketahui kondisi lahan yang sesuai untuk komoditi pertanian yang akan 
dikembangkan lahan untuk meningkatkan produktivitas tanaman kopi (Coffea arabica L.)

\section{BAHAN DAN METODA}

Kecamatan Salak secara administratif merupakan bagian dari Kabupaten Pakpak Bharat, yang berbatasan dengan beberapa Kecamatan dan Kabupaten dengan batas-batas sebagai berikut: Sebelah Utara: Kecamatan Tinada dan Kecamatan Siempat Rube; Sebelah Timur: Kecamatan Sitellu Tali Urang Julu dan Kecamatan Siempat Rube; Sebelah Selatan: Kabupaten Humbang Hasundutan; Sebelah Barat: Kecamatan Pergetteng-getteng Sengkut.

Wilayah Kecamatan Salak memiliki luas $245,57 \mathrm{~km}^{2}$, terdapat areal pertanian persawahan sekitar 2,43 $\mathrm{km}^{2}$, areal pertanian non persawahan sekitar $46,52 \mathrm{~km}^{2}$, areal perkampungan sekitar $4,88 \mathrm{~km}^{2}$, sedangkan sisanya areal hutan sekitar 191,74 $\mathrm{km}^{2}$. Kecamatan Salak merupakan daerah berbukit-bukit, berada pada ketinggian 700$1200 \mathrm{~m}$ dpl dengan kemiringan lereng 0-250, memiliki curah hujan rata-rata $2920 \mathrm{~mm} /$ tahun, temperatur rata-rata tahunan $19,64{ }^{\circ} \mathrm{C}$ dan kelembaban 83,28 \% (Pemkab Pakpak Bharat tahun 2014).

Penelitian dilakukan menggunakan metode survei yang terdiri dari 5 tahap yaitu persiapan, pra-survei, survei utama, analisis tanah di Laboratorium serta pengolahan data. Pengambilan sampel tanah dilakukan dengan cara pemboran pada areal satuan lahan. Satuan lahan dipilih berdasarkan peta satuan unit penggunaan lahan. Berdasarkan penggunaan peta, terdapat sebanyak 6 titik sampel setelah dikompositkan. Penentuan nilai karakteristik lahan untuk sampel tanah dilakukan dengan menggunakan bor tanah pada kedalaman 0-30 $\mathrm{cm}$, dan 30-60 cm. Penentuan sifat kimia tanah dilakukan dengan analisis tanah di Laboratorium Riset dan Teknolgi Fakultas Pertanian USU Medan.

Data penelitian yang diperoleh diinterpretasikan ke dalam kriteria tingkat kesuburan tanah kelas kesesuaian lahan menurut Sys et al. (1993) dan Puslittan (1995). Proses evaluasi lahan ditentukan dengan cara matching (mencocokkan) antara karakteristik lahan dengan persyaratan tumbuh tanaman durian, yang diformulasikan dalam petunjuk teknis evaluasi lahan untuk komoditas pertanian (Hardjowigeno, 2003; Ritung et al., 2011). Pada proses matching digunakan hukum minimum Leibig untuk menentukan faktor pembatas yang akan mempengaruhi kelas dan subkelas kesesuaian lahannya. Hasil kesesuaian lahan komoditi tanaman ditampilkan dalam bentuk tabel kesesuaian lahan aktual dan potensial menggunakan perangkat lunak GIS dan dipetakan kesesuaian lahan aktual dan kesesuian lahan potensialnya.

\section{HASIL DAN PEMBAHASAN}

\section{Karakteristik lahan}

Karakteristik lahan di Areal Penggunaan Lain (APL) diKecamatan Salak,yang sebelumnya merupakan kawasan hutan dan lahan pertanian. Hasil survei lapangan dan analisis contoh tanah di laboratorium disajikan pada Tabel 1.

Dari Tabel 1 dapat diketahui, bahwa lokasi pengamatan dan pengambilan sampel tanah tersebut dapat dikelompokkan ke dalam 8 (delapan) unit lahan (land unit), dengan karakteristik lahan untuk kedalaman 0-30 masing-masing disajikan pada Tabel 1.

Jenis tanah yang terdapat di lahan APL inididominasi Andisol dan terdapat juga jenis tanah Inceptisol. Jenis tanah Andisol dengan greatgroup Hapludands dominan pada pertanian lahan kering. Hapludands adalah tanah yang terbentuk dari bahan induk abu vulkanis. Berdasarkan klasifikasi iklim Oldeman (1975) daerah ini termasuk ke dalam zone iklim (D1) zone iklim yang mempunyai karakteristik 3-4 bulan basah dan $<2$ bulan kering secara berturut-turut. Zona agroekosistem yang didominasipertanian lahan kering dan kawasan hutan dengan bentuk wilayah berbukit, mempunyai kemiringan lereng 2-73 \%. Karakteristik fisik tanahyang mempengaruhiperakarantanamansepertitekstur, drainasedan kedalaman perakaran termasuk cukup baik yaitu drainase tanah baik, tekstur pasir berlempung,lempung berpasir, lempung liat berpasir, serta kedalaman efektif hingga $>$ $100 \mathrm{~cm}$. 
Tabel 1. Karakteristik Lahan Untuk Unit Lahan 1-8 Pada Kedalaman 0-30 cm Di Areal Penggunaan Lain Di Kecamatan Salak Kabupaten Pakpak Bharat Untuk Evaluasi Kesesuaian LahanPertanian.

\begin{tabular}{|c|c|c|c|c|c|c|c|c|}
\hline \multirow{2}{*}{ Karakteristik Lahan } & \multicolumn{8}{|c|}{ Unit Lahan } \\
\hline & 1 & 2 & 3 & 4 & 5 & 6 & 7 & 8 \\
\hline \multicolumn{9}{|l|}{ Temperatur /tc } \\
\hline Temperaturrerata $\left({ }^{0} \mathrm{C}\right)$ & 20 & 20 & 19 & 19 & 21 & 19 & 18 & 21 \\
\hline $\begin{array}{l}\text { Ketinggian tempat } \\
\text { (mdpl) }\end{array}$ & 1024 & 969 & 1139 & 1269 & 965 & 1229 & 1379 & 863 \\
\hline \multicolumn{9}{|l|}{ Ketersediaan air /wa } \\
\hline Curah Hujan(mm) & 2920 & 2920 & 2920 & 2920 & 2920 & 2920 & 2920 & 2920 \\
\hline Lama Bulan Kering & 1 & 1 & 1 & 1 & 1 & 1 & 1 & 1 \\
\hline Zone Agroklimat & D1 & D1 & D1 & D1 & D1 & D1 & D1 & D1 \\
\hline Kelembaban(\%) & 83,28 & 83,28 & 83,28 & 83,28 & 83,28 & 83,28 & 83,28 & 83,28 \\
\hline \multicolumn{9}{|l|}{$\begin{array}{c}\text { Ketersediaan } \\
\text { oksigen/oa }\end{array}$} \\
\hline Drainase & Baik & Baik & baik & Baik & baik & baik & Baik & baik \\
\hline \multicolumn{9}{|l|}{ Media perakaran /rc } \\
\hline Tekstur & $\begin{array}{c}\text { Pasir } \\
\text { Berlempung }\end{array}$ & $\begin{array}{c}\text { Lempung } \\
\text { Berpasir }\end{array}$ & $\begin{array}{l}\text { Lempung } \\
\text { Berpasir }\end{array}$ & $\begin{array}{c}\text { Lempung } \\
\text { Berpasir }\end{array}$ & $\begin{array}{c}\text { Lempung } \\
\text { Berpasir }\end{array}$ & $\begin{array}{c}\text { Lempung } \\
\text { Berpasir }\end{array}$ & $\begin{array}{l}\text { Lempung } \\
\text { Berpasir }\end{array}$ & $\begin{array}{c}\text { Lempung } \\
\text { Liat } \\
\text { Berpasir }\end{array}$ \\
\hline Bahan Kasar(\%) & 6,53 & 8,15 & 4,88 & 5,35 & 8,76 & 5,88 & 7,35 & 4,97 \\
\hline Kedalaman Tanah(cm) & $>100$ & $>100$ & $>100$ & $>100$ & $>100$ & $>100$ & $>100$ & $>100$ \\
\hline \multicolumn{9}{|l|}{ Retensi hara/nr } \\
\hline KTK liat (cmol) & 26,40 & 26,06 & 44,64 & 39,96 & 23,88 & 49,56 & 21,84 & 25,56 \\
\hline Kejenuhan basa (\%) & 16,87 & 19,16 & 12,49 & 15,03 & 21,42 & 13,36 & 24,24 & 20,84 \\
\hline $\mathrm{pH} \mathrm{H}_{2} \mathrm{O}$ & 6,16 & 5,83 & 5,85 & 5,82 & 5,50 & 5,23 & 5,42 & 6,10 \\
\hline C-organik (\%) & 0,56 & 0,88 & 1,00 & 0,73 & 1,00 & 1,34 & 0,71 & 0,41 \\
\hline \multicolumn{9}{|l|}{ Ketersediaan Hara /na } \\
\hline N-total (\%) & 1,14 & 0,29 & 0,36 & 0,46 & 0,41 & 0,51 & 0,55 & 0,06 \\
\hline $\mathrm{P}_{2} \mathrm{O}_{5}$ Bray II (ppm) & 5,81 & 23,66 & 7,09 & 6,74 & 11,40 & 8,49 & 6,51 & 33,90 \\
\hline K-tukar (mg/100g) & 1,544 & 1,263 & 1,676 & 0,987 & 1,649 & 1,894 & 0,947 & 0,672 \\
\hline \multicolumn{9}{|l|}{ Sodisitas /xn } \\
\hline Alkalinitas/ESP (\%) & 1,00 & 1,90 & 1,23 & 1,48 & 1,91 & 1,16 & 2,12 & 1,83 \\
\hline \multicolumn{9}{|l|}{ Bahaya erosi /eh } \\
\hline Lereng $(\%)$ & 22,8 & 12,4 & 23,3 & 74,2 & 7,5 & 27,0 & 43,6 & 2,5 \\
\hline \multicolumn{9}{|l|}{ Bahaya Erosi } \\
\hline \multicolumn{9}{|l|}{ Bahaya banjir/fh } \\
\hline Genangan & F0 & F0 & F0 & F0 & F0 & F0 & F0 & F0 \\
\hline \multicolumn{9}{|l|}{ Penyiapan lahan /lp } \\
\hline Batuan di permukaan & 0 & 0 & 0 & 0 & 0 & 0 & 0 & 0 \\
\hline Singkapan batuan & 0 & 0 & 0 & 0 & 0 & 0 & 0 & 0 \\
\hline
\end{tabular}

Sumber: Data Primer Hasil Analisis Laboratorium Riset Fakultas Pertanian USU (2016). 
Nilai pH tanah di lahan Areal Penggunan Lahan (APL) ini bervariasi dari 5.23 (agak masam) sampai 6,16 (netral), nilai $\mathrm{N}$-total tanah dilahan APLbervariasidari rendah sampai tinggi, nilai $\mathrm{P}_{2} \mathrm{O}_{5}$ tergolong sangat rendah sampai rendah, sedangkan $\mathrm{K}_{2} \mathrm{O}$ tanah pada lahan tersebut memiliki rata-rata tergolong sangat tinggi.

C-Organikdi lahan APL ini tergolong sangat rendah, sehingga sebahagian besar unit lahanperlu penambahan bahan organik. Bahan organik tanah mengandung semua hara termasuk humus yang sangat diperlukan untuk pertumbuhan tanaman. Peran bahan organik terhadap ketersediaan hara dalam tanah tidak terlepas dengan proses mineralisasi, yang merupakan tahap akhir dari proses perombakan bahan organik. Bahan organik memiliki peranan kimia dalam menyediakan $\mathrm{N}, \mathrm{P}$, dan $\mathrm{K}$ untuk tanaman.

Nilai KTK di lahan APL initergolong sedang sampai tinggi. Dengan nilai KTK yang sedang sampai tinggi makatanah mampu menjerap dan menyediakan unsur hara yang lebih banyak, dari pada tanah dengan KTK yang lebih rendah.Nilai KTK suatu tanah dipengaruhi oleh sifat dan jumlah fraksi liat dan bahan organik disamping $\mathrm{pH}$ larutan pengekstrasinya.

Kejenuhan basa di lahan APLini termasuk dalam golongan sangat rendah sampai sedang. Kejenuhan Basa merupakan salah satu indikator kesuburan kimia tanah. Tanahyang subur adalah tanah dengan kejenuhan basa tinggi, sebab belum terjadi pencucian tanah yang serius. Sebaliknya, tanah dengan kejenuhan basa rendah akan menghambat penyerapan unsur hara oleh akar tanaman (Indranada, 1986).

\section{Kesesuaian lahan untuk tanaman Kopi (Coffea arabica L.)}

Faktor-faktor pembatas kesesuaian lahan untuk tanaman kopi yang harus diperbaiki untuk unit lahan 1 sampai 8 pada Tabel 2 adalah, ketersediaan air dan retensi hara kejenuhan basa. Faktor pembatas faktor pembatas temperatur yaitu kelembaban tidak dapat dilakukan usaha perbaikan (S3). Hasil Penelitian Cynthia et.al, (2015) Kesesuaian Lahan dengan Metode Limit untuk Tanaman Kopi Arabika (Coffea Arabica) dan Kopi Robusta (Coffea robusta) di Kecamatan Silima Pungga-pungga Kabupaten Dairi faktor pembatasnya adalah ketersediaan air yaitu kelembaban dan retensi hara yaitu KTK liat dan $\mathrm{pH}$. Faktor pembatas kelembaban tidak dapat diperbaiki karena berhubungan dengan ketinggian tempat yang bersifat permanen. Tetapi faktor retensi hara ini dapat diperbaiki dengan usaha perbaikan dengan pengaplikasian bahan organik dan kapur.

Faktor pembatas kesesuaian lahan aktual dan potensial pada areal penggunaan lain Salak untuk tanaman kopi arabika (Coffea arabica) yaitu curah hujan tahunan yang tinggi dapat dilakukan pengelolaan tata airnya, yaitu dengan pembuatan saluran drainase sehingga kelas kesesuaiannya menjadi tidak cukup sesuai $\left(\mathrm{S}_{3}\right)$ ditinjau dari kesesuaian lahan potensial. Usaha perbaikan yang dapat dilakukan untuk meningkatkan kelas kesesuaian retensi hara kejenuhan basa menjadi cukup sesuai $\left(\mathrm{S}_{3}\right)$, diperlukan pemberian $\mathrm{CaCO}_{3}$ sebanyak 1,87 ton/ha.

Usaha perbaikan yang dapat dilakukan untuk meningkatkan kelas kesesuaian retensi hara C-organik menjadi sangat sesuai $\left(\mathrm{S}_{1}\right)$, diperlukan pemberian bahan organiksebanyak 5,67 ton/ha atau 26,54 ton/ha pupuk organik. Usaha perbaikan yang dapat dilakukan untuk meningkatkan kelas kesesuaian lahan aktual dan potensial pada areal penggunaan lain Salak untuk tanaman kopi arabika (Coffea arabica) dengan ketersediaan hara N-totalmenjadi cukup sesuai $\left(\mathrm{S}_{2}\right)$, diperlukan pemberian Pemupukan 2,6 ton $\mathrm{N} / \mathrm{ha}$ atau setara 5,77 ton urea/ha. Dimana untuk menjadikan N-total $0,21 \%$ (cukup sesuai) yang semula saat penelitian dilapangan sebesar $0,08 \%$, sehingga diperlukan penambahan pemberian bahan organik dan pemupukan untuk dapat hasil yang optimal pada tanaman Kopi di Kecamatan Salak.

Tabel 3.Luas Kesesuaian Lahan Untuk Tanaman Kopi Arabika (Coffea arabicaL.) 
Tabel 2. Rekapitulasi Kesesuaian Lahan Untuk Tanaman Kopi Arabika (Coffea arabicaL.)

\begin{tabular}{|c|c|c|c|}
\hline Land Unit & KLA & Perkiraan Usaha Perbaikan & KLP \\
\hline Unit lahan 1 & $\begin{array}{l}S_{3}-w a, \text { rc, } \\
\text { nr, na, eh }\end{array}$ & $\begin{array}{l}\text { - Pembuatan drainase } \\
\text { - Pengapuran 4,14 ton } \mathrm{CaCO}_{3} / \mathrm{ha} \\
\text { - Pemberian B.O 5,08 ton/ha atau 23,80 ton/ha Pupuk Organik } \\
\text { - Pemupukan } 19,10 \mathrm{~kg} \mathrm{P}_{2} \mathrm{O}_{5} / \mathrm{ha} \text { atau53,06 kg SP36/ha } \\
\text { - Pembuatan teras atau menanam sejajar kontur }\end{array}$ & $\mathrm{S}_{3}$-rc \\
\hline Unit lahan 2 & $\begin{array}{c}\text { S }_{3} \text {-wa, re, } \\
\text { nr }\end{array}$ & $\begin{array}{l}\text { - Pembuatan drainase } \\
\text { - Pengapuran 1,31 ton } \mathrm{CaCO}_{3} / \mathrm{ha} \\
\text { - Pemberian B.O 4,41 ton/ha atau 20,65 ton/ha Pupuk Organik } \\
\text { - Pembuatan teras atau menanam sejajar kontur }\end{array}$ & $\mathrm{S}_{3}-\mathrm{rc}$ \\
\hline Unit lahan 3 & $\begin{array}{l}S_{3}-w a, r c, \\
\text { nr, na, eh }\end{array}$ & $\begin{array}{l}\text { - Pembuatan drainase } \\
\text { - Pengapuran 7,67 ton } \mathrm{CaCO}_{3} / \mathrm{ha} \\
\text { - Pemberian B.O 4,08 ton/ha atau } 19,12 \text { ton/ha Pupuk Organik } \\
\text { - Pemupukan } 18,86 \mathrm{~kg} \mathrm{P}_{2} \mathrm{O}_{5} / \mathrm{ha} \text { atau52,39 kg SP36/ha } \\
\text { - Pembuatan teras atau menanam sejajar kontur }\end{array}$ & $\mathrm{S}_{3}-\mathrm{rc}$ \\
\hline Unit lahan 4 & N-eh & $\begin{array}{l}\text { - Pembuatan drainase } \\
\text { - Pengapuran 8,18 ton } \mathrm{CaCO}_{3} / \mathrm{ha} \\
\text { - Pemberian B.O 3,75ton/ha atau } 17,58 \text { ton/ha Pupuk Organik } \\
\text { - Pemupukan } 18,65 \mathrm{~kg} \mathrm{P}_{2} \mathrm{O}_{5} / \mathrm{ha} \text { atau51,75 kg SP36/ha } \\
\text { - Pembuatan teras atau menanam sejajar kontur }\end{array}$ & $\begin{array}{c}\text { S }_{3}-\mathrm{rc}, \\
\text { eh }\end{array}$ \\
\hline Unit lahan 5 & $\begin{array}{l}\text { S }_{3} \text {-wa, rc, } \\
\text { nr, na }\end{array}$ & $\begin{array}{l}\text { - Pembuatan drainase } \\
\text { - Pengapuran 3,69 ton } \mathrm{CaCO}_{3} / \mathrm{ha} \\
\text { - Pemberian B.O 4,27 ton/ha atau } 20,01 \mathrm{ton} / \mathrm{ha} \text { Pupuk Organik } \\
\text { - Pemupukan } 15,60 \mathrm{~kg} \mathrm{P}_{2} \mathrm{O}_{5} / \mathrm{ha} \text { atau43,33 kg SP36/ha } \\
\text { - Pembuatan teras atau menanam sejajar kontur }\end{array}$ & $\mathrm{S}_{3}-\mathrm{rc}$ \\
\hline Unit lahan 6 & $\begin{array}{l}S_{3}-w a, r c, \\
\text { nr, na, eh }\end{array}$ & $\begin{array}{l}\text { - Pembuatan drainase } \\
\text { - Pengapuran 9,69 ton } \mathrm{CaCO}_{3} / \mathrm{ha} \\
\text { - Pemberian B.O 4,84 ton/ha atau 22,67 ton/ha Pupuk Organik } \\
\text { - Pemupukan 16,88 kg } \mathrm{P}_{2} \mathrm{O}_{5} / \mathrm{ha} \text { atau46,89 kg SP36/ha } \\
\text { - Pembuatan teras atau menanam sejajar kontur }\end{array}$ & $\mathrm{S}_{3}-\mathrm{rc}$ \\
\hline Unit lahan 7 & $\begin{array}{l}S_{3}-w a, \text { rc, } \\
\text { nr, na, eh }\end{array}$ & $\begin{array}{l}\text { - Pembuatan drainase } \\
\text { - Pengapuran 2,23 ton } \mathrm{CaCO}_{3} / \mathrm{ha} \\
\text { - Pemberian B.O 3,05 ton/ha atau } 14,28 \text { ton/ha Pupuk Organik } \\
\text { - Pemupukan 18,63 } \mathrm{kg} \mathrm{P}_{2} \mathrm{O}_{5} / \mathrm{ha} \text { atau51,75 kg SP36/ha } \\
\text { - Pembuatan teras atau menanam sejajar kontur }\end{array}$ & $\mathrm{S}_{3-\mathrm{rc}}$ \\
\hline Unit lahan 8 & $\begin{array}{l}S_{3}-w a, \text { rc, } \\
\text { nr, na, eh }\end{array}$ & $\begin{array}{l}\text { - Pembuatan drainase } \\
\text { - Pengapuran 1,87 ton } \mathrm{CaCO}_{3} / \mathrm{ha} \\
\text { - Pemberian B.O 5,67 ton/ha atau 26,54 ton/ha Pupuk Organik } \\
\text { - Pemupukan } 3 \text { ton N/ha atau6,52 tonUrea/ha }\end{array}$ & $\mathrm{S}_{3}-\mathrm{rc}$ \\
\hline
\end{tabular}

Keterangan : $\quad \mathrm{KLA}=$ Kesesuaian Lahan Aktual $\quad \mathrm{KLP}=$ Kesesuaian Lahan Potensial 
Tabel 3.Luas Kesesuaian Lahan Untuk Tanaman Kopi Arabika (Coffea arabicaL.)

\begin{tabular}{|c|c|c|c|c|}
\hline Unit Lahan & $\begin{array}{c}\text { Kesesuaian lahan } \\
\text { aktual }\end{array}$ & $\begin{array}{c}\text { Kesesuaian lahan } \\
\text { potensial }\end{array}$ & Luas (Ha) & Persentase (\%) \\
\hline 1 & $\mathrm{~S}_{3}$-wa, rc, nr, na, eh & $\mathrm{S}_{3}-\mathrm{rc}$ & 74,46 & 2,06 \\
\hline 2 & $\mathrm{~S}_{3}$-wa, rc, nr & $\mathrm{S}_{3}-\mathrm{rc}$ & 1799,90 & 49,90 \\
\hline 3 & $\mathrm{~S}_{3}$-wa, rc, nr, na, eh & $\mathrm{S}_{3}$-rc & 432,14 & 11,98 \\
\hline 4 & $\mathrm{~N}-\mathrm{eh}$ & $\mathrm{S}_{3}-\mathrm{rc}, \mathrm{eh}$ & 38,32 & 1,06 \\
\hline 5 & $\mathrm{~S}_{3}$-wa, rc, nr, na & $\mathrm{S}_{3}-\mathrm{rc}$ & 467,88 & 12,97 \\
\hline 6 & $\mathrm{~S}_{3}$-wa, rc, nr, na, eh & $\mathrm{S}_{3}$-rc & 131,70 & 3,65 \\
\hline 7 & $\mathrm{~S}_{3}$-wa, rc, nr, na, eh & $\mathrm{S}_{3}-\mathrm{rc}$ & 130,81 & 3,63 \\
\hline 8 & $\mathrm{~S}_{3}$-wa, rc, nr, na, eh & $\mathrm{S}_{3}-\mathrm{rc}$ & 531,99 & 14,75 \\
\hline \multicolumn{3}{|c|}{ Total } & 3607,20 & 100,00 \\
\hline
\end{tabular}

Sumber : Hasil Analisis GIS

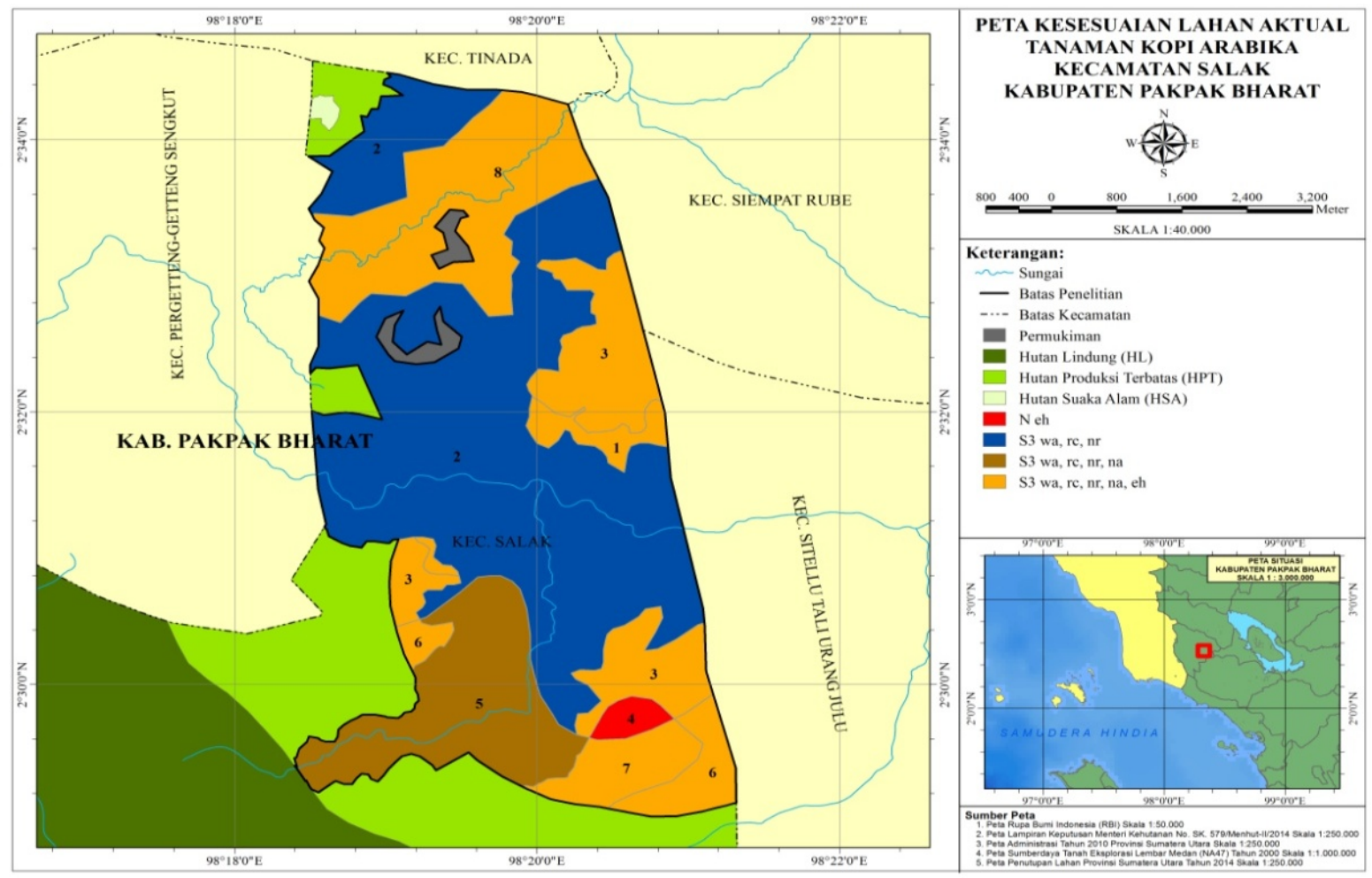

Gambar 3. Peta Kesesuaian LahanPotensial Tanaman Kopi Arabika (Coffea arabica L.) Di Lahan Areal Penggunaan Lain Kecamatan Salak, Kabupaten Pakpak Bharat 


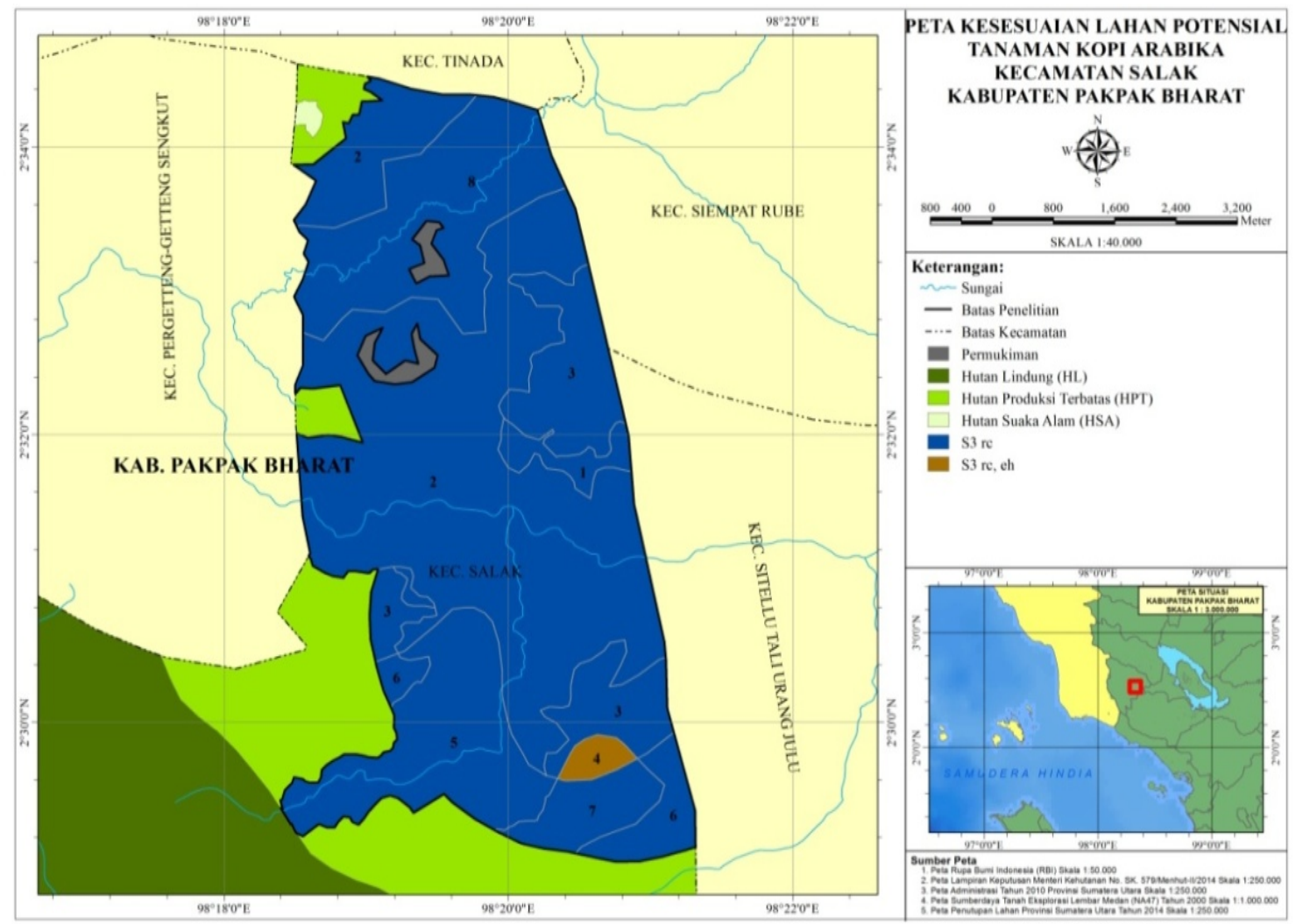

Gambar 4. Peta Kesesuaian LahanPotensial Tanaman Kopi Arabika (Coffea arabica L.) Di Lahan Areal Penggunaan Lain Kecamatan Salak, Kabupaten Pakpak Bharat

\section{KESIMPULAN}

Faktor pembatas ketersedian air (wa), media perakaran (rc), retensi hara (nr), ketersediaan hara (na) dan bahaya erosi (eh). Usaha perbaikan yang dapat dilakukan yaitu pembuatan drainase, pembuatan teras atau menanam sejajar kontur, pengapuran $\mathrm{CaCo} 3$, pemberian bahan organik dan pemupukan.

\section{DAFTAR PUSTAKA}

Arief, M. C. W., M. Tarigan, R. Saragih, I. Lubis, dan F. Rahmadani. 2011. Panduan Sekolah Lapangan: Budidaya Kopi Konservasi, Berbagi Pengalaman dari Kabupaten Dairi Sumatera Utara. Conservation International Indonesia. Jakarta.

Cynthia S., Posma M., dan Mariani S. 2015. Evaluasi Kesesuaian Lahan dengan Metode Limit untuk Tanaman Kopi
Arabika (Coffea Arabica) dan Kopi Robusta (Coffea robusta Lindl.) di Kecamatan Silima Pungga-pungga Kabupaten Dairi. Fakultas Pertanian Universitas Sumatra Utara. Medan. Vol.3 (2) p: $433-445$

Djomantara, S. dan N. Rachmawati. 2000. Cara Pemilihan Lahan Berpotensi untuk Pengembangan Pertanian Suatu Wilayah. Buletin Teknik Pertanian 5: 41-42.

Hardjowigeno, S. 2003. Ilmu Tanah. Akademika Pressindo. Jakarta.

Hutapea, S. 1991. Evaluasi Metode Kesesuaian Lahan untuk Budidaya Kakao Lindak di Jawa Barat. Tesis. Program Pascasarjana, IPB, Bogor. 
Hermon, Khairani, 2009. Geografi Tanah (Suatu Tinjauan Teoritis, Metodologis, dan aplikasi proposal penelitian).Yayasan Jihadul Center, Padang. Http :// Dedihermon.blogspot.com/? View = sidebar 10/05/2018 12.30 PM

Karim, A., 2007. Pengembangan Kopi Arabika Organik Di Bener Meriah. Makalah disajikan pada Acara :Pelatihan Penuyuluh Pertanian Lapangan Kabupaten Bener Meriah, Pondok Gajah, 10 - 12 Desember 2007.

Indranada, H. K. 1986. Pengelolaan kesuburan tanah. Bina Aksara, Jakarta. $90 \mathrm{hlm}$. No. ISBN 979-511-672-2

Mukhlis. 2007. Analisis Tanah dan Tanaman. USU Press, No. ISBN 979-458-312-X Medan.

Oldeman, L.R. 1975. The. Agrodimatic Map of Java and Madura, Bogor. Contributions from the Central Research Institute for Agriculture.

Pemkab Pakpak Bharat 2014. Pemerintah Kabupaten Pakpak Bharat. www.sumutprov.go.id. Diakses tanggal 11 April 2016.

Rubiyo, J. Rinaldi dan Suharyanto., 2003. Kajian Rehabilitasi Tanaman Kopi Robusta dengan Kopi Arabika dengan Teknik Sambung di Kabupaten Bangle Bali. Pengkajian Teknologi Pertanian Bali, Bali.

Puslittan, Badan Litbangtan, Kementerian Pertanian Republik Indonesia, 1995. Evaluasi Kesesuaian Lahan.

Sys, C. ,E. Van Ranst, J. Debaveye, and F. Beernaert.1993. Land Evaluation. Crop Requirements Part III. Agricultural Publication No.7. General Administration for Development Corp. 1050 Brussels- Belgium.

Ritung, S., K. Nugrho, A. Mulyani, dan E. Suryani. 2011. Petunjuk Teknis Evaluasi Lahan Untuk Komoditas Pertanian. Balai Besar Penelitian dan Pengembangan Sumberdaya Lahan Pertanian, Puslitbangtanak, Badan Penelitian dan Pengembangan Pertanian. Bogor. hlm 159. 